\title{
BMJ Open Association between platelet count and hepatocellular carcinoma overall survival: a large retrospective cohort study
}

\author{
Linbin Lu, ${ }^{1}$ Zhimin Su, ${ }^{2}$ Peichan Zheng, ${ }^{3}$ Zhixian $\mathrm{Wu},{ }^{4}$ Yan Zhang, ${ }^{1}$ Huimin $\mathrm{He},{ }^{1}$ \\ Jingnan Liu, ${ }^{1}$ Shan Lin, ${ }^{5}$ Xiong Chen (1) ${ }^{1}$
}

To cite: Lu L, Su Z, Zheng P, et al. Association between platelet count and hepatocellular carcinoma overall survival: a large retrospective cohort study. BMJ Open 2020;10:e038172. doi:10.1136/ bmjopen-2020-038172

- Prepublication history and additional materials for this paper is available online. To view these files, please visit the journal online (http://dx.doi. org/10.1136/bmjopen-2020038172).

$\mathrm{LL}, \mathrm{ZS}, \mathrm{PZ}$ and ZW contributed equally.

Received 02 March 2020 Revised 01 September 2020 Accepted 13 September 2020

Check for updates

(C) Author(s) (or their employer(s)) 2020. Re-use permitted under CC BY-NC. No commercial re-use. See rights and permissions. Published by BMJ.

For numbered affiliations see end of article.

Correspondence to

Dr Xiong Chen;

cxiongzpc@fjmu.edu.cn

\section{ABSTRACT}

Objectives To explore the non-linear relationship between platelet count (PLT) and hepatocellular carcinoma (HCC) overall survival (OS).

Setting The study was done in Sun Yat-sen University Cancer Center (SYSUCC) from January 2007 to May 2012, a total of 5005 consecutive participants at SYSUCC were retrospectively reviewed, and 979 patients with Barcelona clinic liver cancer (BCLC) stage B were selected for the final analysis.

Participants A total of 979 newly diagnosed patients with HCC with BCLC stage B were identified for the secondary analysis. Eight cases were excluded for missing data of PLT.

Main outcome measures Cox proportional hazard regression models were used to calculate multivariableadjusted HRs and 95\% Cls for HCC. The non-linear relationship was estimated through a restricted cubic spline regression, and a two-piecewise Cox proportional hazards model was further performed to calculate the threshold effect. We used multiple imputation to deal with the missing data.

Results In the multivariate analysis, Log PLT was associated with a $91 \%$ risk increase in death (HR 1.91; 1.28 to 2.85) with adjustment for gender, Child-Pugh class, age $\times$ diameter of main tumour, both lobe with lesions $\times$ number of the intrahepatic lesions, alpha-fetoprotein $(<25, \geq 25)$ and lactic dehydrogenase $(<245, \geq 245)$. We also found a U-shape relationship between PLT and HCC OS at the inflexion point of $67.6 \times 10^{9} / \mathrm{L}$. The HR was 0.12 (95\% Cl 0.03 to 0.52) for Log PLT $\leq 10.83$ and 3.07 (Cl 1.91 to 4.92 ) for Log PLT>10.83 after adjusting for potential confounders. The core results were consistent with those from the sensitivity analysis. Besides, a significantly higher hazard risk was found in the patients with age $<55$, both lobes with lesions, tumour diameter $>50$, haemoglobin $\geq 120$ and $C$ reactive protein $>10$.

Conclusion PLT was nonlinearly associated with HCC OS.

\section{INTRODUCTION}

Hepatocellular carcinoma (HCC) is the second cancer-related death cause in men worldwide $^{1}$ and the fifth major cause of death in China. ${ }^{2}$ The majority of patients with HCC is diagnosed at an advanced stage,
Strengths and limitations of this study

- This is the large-scale, well-characterised realworld data with long follow-up duration.

- The U-shaped relationship and threshold effect were calculated between platelet count and hepatocellular carcinoma overall survival.

- The non-linear and interaction of cofounding factors were taken into consideration.

- A limitation is the unmeasured confounders and innate limitation of data from the freely obtained database.

with a median overall survival (OS) no more than 1 year. ${ }^{3}$ Although some antiviral medicines, such as nucleoside analogue therapy, can effectively minimise HCC risk among populations with chronic hepatitis $\mathrm{B}^{4}$ and reduce recurrence risk among hepatitis $\mathrm{B}$ virus (HBV)-related patients with HCC after liver resection, ${ }^{5}$ the risk is not eradicated. With such a poor prognosis, biomarkers are urgently needed to predict the incidence and mortality of HCC.

Recent evidence shows that platelets act as critical factors in HCC proliferation ${ }^{6}$ and contribute to distant metastasis, probably through the adhesion receptors glycoprotein(GP) IIb, GPIb-IX-V and p-selectin. ${ }^{7}$ Regarding non-alcoholic steatohepatitis (NASH), however, platelet-derived GPIb alpha was a mediator in the development of NASH and subsequent HCC. ${ }^{8}$ Numerous platelet count (PLT)-containing predictive models have been built to identify HCC risk $^{9-12}$ and evaluate the prognosis or recurrence of patients after curative resection for $\mathrm{HCC}^{13-15}$ at an early stage. Moreover, a higher aspartate aminotransferase-to-platelet ratio index is associated with worse survival ${ }^{16}$ in patients treated with transarterial chemoembolisation (TACE). However, all of these 
predictive models fail to illuminate the relationship between platelets and HCC risk or OS, which provides indirect evidence for antiplatelet therapy.

Several clinical studies have indicated a correlation between high PLT and an increased risk of distant metas$\operatorname{tasis}^{1718}$ and recurrence after liver transplantation ${ }^{19}$ in patients with HCC. In line with this finding, another large retrospective study showed that lower PLT is associated with a better outcome in patients with advanced HCC. ${ }^{20}$ However, few pieces of evidence revealed the relationship between PLT and clinical outcome for the patients with intermediate-stage HCC, which contained a variety of tumour burden, hepatic function (Child-Pugh score 5-10) and disease aetiology. To address this issue, we retrospectively investigated the association between PLT and OS in patients with HCC with Barcelona clinic liver cancer (BCLC) stage B.

\section{METHODS AND PATIENTS}

\section{Patient and public involvement}

This is a retrospective multicentre cohort study conducted by Lujun Shen $e t a l^{21}$ at three affiliated hospitals of Sun Yat-sen University and the Second Hospital of Guangzhou Medical University. In the above-mentioned medical centres, most patients $(1852 / 2020,91.7 \%)$ were treated TACE as their first-line treatment; $135(6.7 \%)$ patients received surgical resection and $33(1.6 \%)$ patients refused to receive treatment. The later therapies after TACE include ablative therapies, surgical resection, targeted therapies or palliative chemotherapy. ${ }^{21}$

PLT data from Sun Yat-sen University Cancer Center (SYSUCC) were freely obtained from the Dryad Digital Repository database. A total of 979 participants newly diagnosed with HCC at SYSUCC were recruited and selected according to the inclusion criteria (see online supplemental figure S1). Of the 979 participants, 8 patients were excluded from the final analysis because of missing PLT data.

The study protocol (2017-FXY-129) was approved by the department of clinical research at SYSUCC. Because this was a secondary analysis study, and the data were anonymous, the requirement for informed consent was waived. Patients or the public were not involved in the design, or conduct, or reporting or dissemination plans of our research.

\section{Definition and measurement}

We defined OS as the time from diagnosis to death by any cause. To simplify the classification, HBV/HCV, the subgroup of cause and type of hepatitis, was defined as HBV, HCV or both and no viral/other as no viral or other cause of hepatitis. Moreover, both lobes with lesions were defined as lesions in both the left and right lobes of the liver. Only the baseline data on serum tumour markers, medical imaging and biochemical and haematological indices were included in the analysis.

\section{Statistical analysis}

To test the hypothesis that PLT is associated with HCC OS, our statistical analyses included two main steps.

We first examined the distribution of the PLT level $\left(10^{9} / \mathrm{L}\right)$. The distribution of PLT was skewed towards the left and transformed to the $\log 10$ scale (Log PLT) for analysis. We then divided the study population into two groups based on the turning point of Log PLT. The baseline characteristics of the different groups were compared using the $\chi^{2}$ test for categorical variables. To explore the relationship between PLT and HCC OS, we performed univariate analysis and multivariate analysis based on the Cox proportional hazards model. The covariances, when added to the basic model or removed from the full model, produced over $10 \%$ change in the regression coefficient of PLT and were adjusted in multivariate analysis (see online supplemental table S1). In the multivariate analysis, we simultaneously showed the results from the unadjusted and fully adjusted analysis model. Subgroup analyses were performed using stratified Cox proportional hazards models, and interactions of subgroups were inspected by likelihood ratio tests.

To identify a non-linear relationship, we applied a smooth curve technique to estimate the shape between Log PLT and hazard risk through a restricted cubic spline regression. A two-piecewise Cox proportional hazards model was further performed to calculate the threshold effect of Log PLT on OS using a smoothing plot. The inflexion point was determined using the recursive method, where the maximum model likelihood was used. Furthermore, we conducted a $\log$ likelihood ratio test comparing the one-line linear regression.

In the second main step, as a sensitivity analysis, we used three approaches further to evaluate the relationship between PLT and OS in HCC. To address the non-linearity of confounding factors, we first set up a model adjusted for AFP (smooth), lactic dehydrogenase (LDH) (smooth) and other confounders through restricted cubic spline. This method was also performed to confirm the shape of Log PLT with the log HR. We then performed sequential landmark analyses to evaluate the relationship between PLT and OS for patients surviving a minimum of 3, 6, 9 and 12 months from diagnosis. The threshold effect was further checked in the subgroup of patients at each sequential landmark. To maximise statistical power and minimise bias, which may occur if confounders with missing data are excluded from analysis, we finally used multiple imputation (MI), based on five replications and the Markov-chain Monte Carlo method in the R MI procedure, to account for missing data on Child-Pugh class, cause and type of hepatitis, both lobe with lesions, AFP and LDH. We then established an MI cohort to perform sensitivity analyses using a complete-case analysis.

All analyses were performed using Empower (R) (www. empowerstats.com, X\&Y Solutions, Boston, Massachusetts, USA). 


\section{RESULTS}

\section{Patient and baseline characteristics}

From January 2007 to May 2012, a total of 5005 consecutive participants at SYSUCC were retrospectively reviewed, and 791 patients with BCLC stage B were selected for the final analysis. All of the patients were class 0 of WHO performance status, with a median age of 55 (range, 14-85) years. $\mathrm{HBV} / \mathrm{HCV}$ was the leading cause of HCC $(860 / 97188.6 \%)$. And only 16 patients (16/971, 2.0\%) had HCC induced by no viral or other causes. By the deadline of the study, 549 (56.5\%) patients had died. The median follow-up time for the death was 10.8 months (range, 0.2-81.4) and 27.6 months (range, 0.1-115.3) for those who were censored.

As shown in table 1, the patients' baseline characteristics were presented by the turning point of Log PLT. There were significant differences in the baseline characteristics between each group, including age, Child-Pugh class, number of intrahepatic lesions, diameter of the main tumour and haemoglobin (Hgb), LDH, white cell count and $\mathrm{C}$ reactive protein (CRP) levels.

\section{Univariate and multivariate analyses of PLT and OS}

As reported in table 2, in the univariate analysis, we found that both lobes with lesion (HR 1.51; 95\% CI 1.27 to 1.80 ), intrahepatic lesion $>3$ (HR $1.57 ; 1.32$ to 1.87 ), main tumour $>50 \mathrm{~mm}$ (HR 2.24; 1.85 to 2.72 ), $\mathrm{AFP} \geq 25 \mathrm{ng} /$ $\mathrm{mL}$ (HR $1.60 ; 1.32$ to 1.95 ) and $\mathrm{LDH} \geq 245 \mathrm{U} / \mathrm{L}$ (HR 1.60; 1.35 to 1.90 ) were associated with higher death risk, but $\mathrm{CRP} \leq 10 \mathrm{mg} / \mathrm{L}$ was associated with a lower risk. Based on clinical and statistical reasons (see online supplemental table S1), we chose confounding factors including sex, age, Child-Pugh class, diameter of the main tumour, both lobes with lesions, number of intrahepatic lesions, AFP and LDH. We found that there were interactions between age and diameter of the main tumour, both lobes with lesions and number of intrahepatic lesions (all $\mathrm{p}<0.05$ ). Thus, we adjusted for sex, Child-Pugh class, age $\times$ diameter of the main tumour, both lobes with lesions $\times$ number of intrahepatic lesions, AFP $(<25, \geq 25)$ and LDH $(<245, \geq 245)$ as the confounders. In table $3, \log$ PLT was associated with a $73 \%$ increase in the risk of death (unadjusted HR 1.73; 1.20 to 2.52). After adjusting for confounding factors, the positive relationship was still robust (HR 1.91; 1.28 to 2.85 ). However, compared with Log PLT $\leq 10.83$, Log PLT was not significantly associated with an increase in death (adjusted HR 1.08; 0.81 to 1.44$)$.

When stratified by age, the crude HR was 4.28 (95\% CI 2.35 to 7.78 ) for age $<55$ and 0.85 (CI 0.52 to 1.38 ) for age $\geq 55$. The interaction test between age groups was statistically significant $(\mathrm{p}<0.0001)$. Similarly, both lobes with lesions (HR 2.72; CI 1.69 to 4.38), tumour diameter $>50$ (HR 1.65; CI 1.06 to 2.59), Hgb $\geq 120$ (HR 2.31; CI 1.46 to 3.66) and CRP $>10$ (HR 2.24; CI 1.40 to 3.56) were significantly different in each subgroup (all $\mathrm{p}$ for interaction $<0.05$ ), which is shown in figure 1.
Table 1 Baseline characteristics of patients in the subgroups of Log PLT

\begin{tabular}{|c|c|c|c|}
\hline \multirow[b]{2}{*}{ Characteristics } & \multicolumn{2}{|l|}{ Log PLT(1/L) } & \multirow[b]{2}{*}{$P$ value } \\
\hline & $\leq 10.83$ & $>10.83$ & \\
\hline $\mathrm{N}$ & 102 & 869 & - \\
\hline Gender & & & 0.577 \\
\hline Male & $91(89.2 \%)$ & $790(90.9 \%)$ & - \\
\hline Female & $11(10.8 \%)$ & $79(9.1 \%)$ & - \\
\hline Age (year) & & & $<0.001$ \\
\hline$<55$ & $27(26.5 \%)$ & $453(52.1 \%)$ & - \\
\hline$\geq 55$ & 75 (73.5\%) & $416(47.9 \%)$ & - \\
\hline Child-Pugh class & & & $<0.001$ \\
\hline A & $74(75.5 \%)$ & $771(90.4 \%)$ & - \\
\hline B & $24(24.5 \%)$ & $82(9.6 \%)$ & - \\
\hline Cause and type of hepatitis & & & 0.559 \\
\hline No viral/other & $1(1.1 \%)$ & $15(1.9 \%)$ & - \\
\hline $\mathrm{HBV} / \mathrm{HCV}$ & 93 (98.9\%) & $767(98.1 \%)$ & - \\
\hline Both lobe with lesions & & & 0.747 \\
\hline No & $44(43.6 \%)$ & $364(41.9 \%)$ & - \\
\hline Yes & $57(56.4 \%)$ & $505(58.1 \%)$ & - \\
\hline Number of intrahepatic lesions & & & 0.037 \\
\hline$\leq 3$ & $31(30.4 \%)$ & 357 (41.1\%) & - \\
\hline$>3$ & $71(69.6 \%)$ & $512(58.9 \%)$ & - \\
\hline Diameter of main tumour $(\mathrm{mm}$ & & & $<0.001$ \\
\hline$\leq 50$ & $61(59.8 \%)$ & $266(30.6 \%)$ & - \\
\hline$>50$ & $41(40.2 \%)$ & $603(69.4 \%)$ & - \\
\hline $\operatorname{AFP}(\mathrm{ng} / \mathrm{mL})$ & & & 0.508 \\
\hline$<25$ & $31(31.6 \%)$ & $234(28.4 \%)$ & - \\
\hline$\geq 25$ & $67(68.4 \%)$ & $589(71.6 \%)$ & - \\
\hline Haemoglobin (g/L) & & & $<0.001$ \\
\hline$<120$ & $46(45.1 \%)$ & $188(21.6 \%)$ & - \\
\hline$\geq 120$ & $56(54.9 \%)$ & $681(78.4 \%)$ & - \\
\hline LDH (U/L) & & & 0.041 \\
\hline$<245$ & $65(63.7 \%)$ & $460(53.1 \%)$ & - \\
\hline$\geq 245$ & $37(36.3 \%)$ & 407 (46.9\%) & - \\
\hline WBC $\left(10^{9} / L\right)$ & & & 0.042 \\
\hline$<11$ & $91(91.0 \%)$ & $713(83.1 \%)$ & - \\
\hline$\geq 11$ & $9(9.0 \%)$ & 145 (16.9\%) & - \\
\hline $\mathrm{CRP}(\mathrm{mg} / \mathrm{L})$ & & & 0.03 \\
\hline$\leq 10$ & $48(47.5 \%)$ & $503(58.8 \%)$ & - \\
\hline$>10$ & $53(52.5 \%)$ & $352(41.2 \%)$ & - \\
\hline
\end{tabular}

Numbers that do not add up to 971 are attributable to missing data.

The $\chi^{2}$ test was performed to compare the differences.

AFP, Alpha-fetoprotein; CRP, C reactive protein; HBV, Hepatitis B virus; HCV, Hepatitis C virus; $L D H$, lactic dehydrogenase; Log PLT, logarithm platelet count; WBC, white blood cell.

Non-linear relationship and threshold effect of Log PLT on OS After adjusting for potential confounders, including sex, Child-Pugh class, age $\times$ diameter of the main tumour, both lobes with lesions $\times$ number of intrahepatic lesions, 
Table 2 Univariate analysis for risk factors of overall survival in hepatocellular carcinoma at BCLC stage B

\begin{tabular}{lll}
\hline Characteristics & Value $(\mathbf{n}=\mathbf{9 7 1})$ & Odds ratio $(\mathbf{9 5 \%} \mathbf{C l})$ \\
\hline $\begin{array}{lll}\text { Gender } \\
\text { Male }\end{array}$ & $881(90.73 \%)$ & Reference \\
Female & $90(9.27 \%)$ & $1.18(0.89$ to 1.58$)$ \\
Age (year ) & & \\
$<55$ & $480(49.43 \%)$ & Reference \\
$\geq 55$ & $491(50.57 \%)$ & $0.93(0.78$ to 1.10$)$ \\
Child-Pugh class; missing $n=20$ & \\
\hline A & $845(88.88 \%)$ & Reference \\
B & $106(11.12 \%)$ & $1.25(0.91$ to 1.71$)$ \\
\hline
\end{tabular}

Cause and type of hepatitis; missing $n=95$

\begin{tabular}{|c|c|c|}
\hline No viral/other & $16(1.83 \%)$ & Reference \\
\hline $\mathrm{HBV} / \mathrm{HCV}$ & $860(98.17 \%)$ & $0.81(0.43$ to 1.52$)$ \\
\hline \multicolumn{3}{|c|}{ Both lobe with lesions; missing $n=1$} \\
\hline No & $408(42.06 \%)$ & Reference \\
\hline Yes & $562(57.94 \%)$ & $1.51(1.27$ to 1.80$)$ \\
\hline \multicolumn{3}{|c|}{ Number of intrahepatic lesions } \\
\hline$\leq 3$ & $388(39.96 \%)$ & Reference \\
\hline$>3$ & $583(60.04 \%)$ & 1.57 (1.32 to 1.87$)$ \\
\hline \multicolumn{3}{|c|}{ Diameter of main tumour(mm ) } \\
\hline$\leq 50$ & $327(33.68 \%)$ & Reference \\
\hline$>50$ & $644(66.32 \%)$ & 2.24 (1.85 to 2.72$)$ \\
\hline \multicolumn{3}{|c|}{ AFP (ng/mL); missing $n=50$} \\
\hline$<25$ & $265(28.77 \%)$ & Reference \\
\hline$\geq 25$ & $656(71.23 \%)$ & $1.60(1.32$ to 1.95$)$ \\
\hline \multicolumn{3}{|l|}{$\begin{array}{l}\text { Haemoglobin } \\
(\mathrm{g} / \mathrm{L})\end{array}$} \\
\hline$<20$ & $234(24.10 \%)$ & Reference \\
\hline$\geq 20$ & $737(75.90 \%)$ & $0.95(0.78$ to 1.15$)$ \\
\hline \multicolumn{3}{|c|}{ LDH (U/L); missing n=2 } \\
\hline$<245$ & $525(54.18 \%)$ & Reference \\
\hline$\geq 245$ & $444(45.82 \%)$ & $1.60(1.35$ to 1.90$)$ \\
\hline \multicolumn{3}{|c|}{ WBC $\left(10^{9} / L\right) ;$ missing $n=13$} \\
\hline$<11$ & $804(83.92 \%)$ & Reference \\
\hline$\geq 11$ & $154(16.08 \%)$ & $1.07(0.85$ to 1.34$)$ \\
\hline \multicolumn{3}{|c|}{ CRP (mg/L); missing $n=15$} \\
\hline$>10$ & $551(57.64 \%)$ & Reference \\
\hline$\leq 10$ & 405 (42.36\%) & 0.82 (0.69 to 0.97$)$ \\
\hline
\end{tabular}

Numbers that do not add up to 971 are attributable to missing data.

AFP, Alpha-fetoprotein; BCLC, Barcelona clinic liver cancer; CRP, C reactive protein; HBV, Hepatitis $B$ virus; HCV, Hepatitis $C$ virus; $\mathrm{LDH}$, lactic dehydrogenase; WBC, white blood cell.

AFP $(<25, \geq 25)$ and LDH $(<245, \geq 245)$, a U-shaped relationship between PLT (Log PLT) and OS was observed (figure 2). The latter increased with decreasing PLT after the turning point $\left(\log\right.$ PLT $=10.83$, PLT $\left.=67.6 \times 10^{9} / \mathrm{L}\right)$.
Table 3 Platelet count and multivariate HR of overall survival with $95 \% \mathrm{Cls}$ in hepatocellular carcinoma at BCLC stage $B$

\begin{tabular}{|c|c|c|c|c|}
\hline & $\begin{array}{l}\text { Deaths/ } \\
\text { patients* }\end{array}$ & $\begin{array}{l}\text { Not } \\
\text { adjusted }\end{array}$ & Model I† & Model II¥ \\
\hline \multicolumn{5}{|l|}{ Initial cohort } \\
\hline Lg PLT (1/L) & $517 / 904$ & $\begin{array}{l}1.73(1.20 \\
\text { to } 2.52)\end{array}$ & $\begin{array}{l}1.91(1.28 \\
\text { to } 2.85)\end{array}$ & $\begin{array}{l}1.72(1.15 \text { to } \\
2.59)\end{array}$ \\
\hline \multicolumn{5}{|l|}{ Lg PLT (1/L) } \\
\hline $\begin{array}{c}\leq 10.83 \\
(\mathrm{PLT} \leq 67.6)\end{array}$ & - & Reference & Reference & Reference \\
\hline $\begin{array}{c}>10.83 \\
(\mathrm{PLT}>67.6)\end{array}$ & $462 / 810$ & $\begin{array}{l}1.03(0.79 \\
\text { to } 1.36)\end{array}$ & $\begin{array}{l}1.08(0.81 \\
\text { to } 1.44)\end{array}$ & $\begin{array}{l}1.02(0.76 \text { to } \\
1.36)\end{array}$ \\
\hline \multicolumn{5}{|l|}{ MI cohort } \\
\hline Lg PLT (1/L) & $549 / 971$ & $\begin{array}{l}1.73(1.20 \\
\text { to } 2.52)\end{array}$ & $\begin{array}{l}2.09(1.43 \\
\text { to } 3.06)\end{array}$ & $\begin{array}{l}1.88 \text { (1.28 to } \\
2.78)\end{array}$ \\
\hline \multicolumn{5}{|l|}{ Lg PLT (1/L) } \\
\hline $\begin{array}{c}\leq 10.83 \\
(\mathrm{PLT} \leq 67.6)\end{array}$ & - & Reference & Reference & Reference \\
\hline $\begin{array}{c}>10.83 \\
(\mathrm{PLT}>67.6)\end{array}$ & $491 / 869$ & $\begin{array}{l}1.03(0.79 \\
\text { to } 1.36)\end{array}$ & $\begin{array}{l}1.10(0.84 \\
\text { to } 1.45)\end{array}$ & $\begin{array}{l}1.04 \\
(0.79,1.38)\end{array}$ \\
\hline
\end{tabular}

*Numbers that do not add up to 971 are attributable to missing data.

†This model was adjusted of gender, Child-Pugh class (A, B), age $(<55, \geq 55) \times$ diameter of main tumour $(\leq 50,>50)$, both lobe with lesions (no, yes) $\times$ number of the intrahepatic lesions $(\leq 3,>3)$, AFP $(<25, \geq 25)$, LDH $(<245, \geq 245)$.

$\ddagger$ This model was adjusted of gender, Child-Pugh class (A, B), age $(<55, \geq 55) \times$ diameter of main tumour $(\leq 50,>50)$, both lobe with lesions (no, yes) $\times$ No. of the intrahepatic lesions $(\leq 3,>3)$, AFP (smooth), LDH (smooth).

AFP, Alpha-fetoprotein; BCLC, Barcelona clinic liver cancer; LDH, lactic dehydrogenase; Lg PLT, logarithm platelet count; MI, multiple imputation.

The threshold effect of Log PLT on OS was significant with adjustment for the confounders $(\mathrm{p}<0.001)$. The HR was 0.12 (95\% CI 0.03 to 0.52$)$ for $\log$ PLT $\leq 10.83$ and 3.07 (CI 1.91 to 4.92 ) for $\log$ PLT>10.83 (see table 4).

\section{Sensitivity analyses}

In the sensitivity analyses, we first set up model II that adjusted for sex, Child-Pugh class, age $\times$ diameter of the main tumour, both lobes with lesions $\times$ number of intrahepatic lesions, AFP (smooth) and LDH (smooth) through restricted cubic spline. The results were consistent with those of model I (table 3 ).

Second, in figure 3, we found that the HRs were 1.66 (95\% CI 1.09 to 2.52), 1.50 (CI 0.94 to 2.39), 1.12 (CI 0.67 to 1.89 ) and 1.12 (CI 0.67 to 1.89 ) for patients surviving $>3,>6,>9$ and $>12$ months, respectively, based on the Cox proportional hazards models after adjusting for sex, Child-Pugh class, age $\times$ diameter of the main tumour, both lobes with lesions $\times$ number of intrahepatic lesions, AFP $(<25, \geq 25)$ and LDH $(<245, \geq 245)$. Moreover, we also found that the threshold effect at the turning point (Log PLT=10.83) was significant for patients surviving $>3(\mathrm{p}=0.012)$ and $>6$ months $(\mathrm{p}=0.009)$ but not for those surviving $>9$ and $>12$ months (all $\mathrm{p}>0.05$ ). 

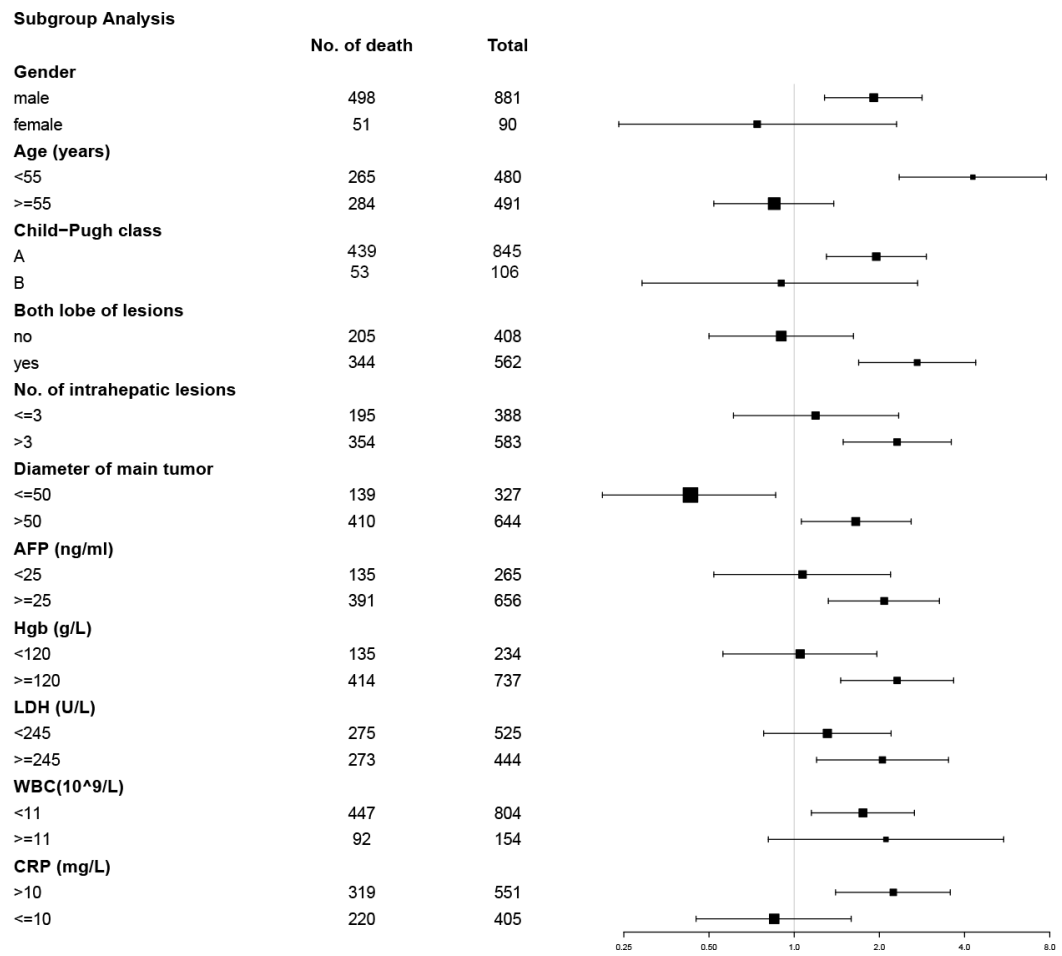

\begin{tabular}{|c|c|}
\hline $\mathrm{HR}(95 \% \mathrm{Cl})$ & $\begin{array}{c}P \text { for interaction } \\
0.108\end{array}$ \\
\hline \multicolumn{2}{|l|}{$1.91(1.28,2.83)$} \\
\hline \multicolumn{2}{|l|}{$0.74(0.24,2.30)$} \\
\hline & $<0.0001$ \\
\hline \multicolumn{2}{|l|}{$4.28(2.35,7.78)$} \\
\hline \multicolumn{2}{|l|}{$0.85(0.52,1.38)$} \\
\hline & 0.193 \\
\hline \multicolumn{2}{|l|}{$1.96(1.29,2.97)$} \\
\hline \multicolumn{2}{|l|}{$1.29(0.48,3.42)$} \\
\hline & 0.005 \\
\hline \multicolumn{2}{|l|}{$0.90(0.50,1.62)$} \\
\hline \multicolumn{2}{|l|}{$2.72(1.69,4.38)$} \\
\hline & 0.105 \\
\hline \multicolumn{2}{|l|}{$1.19(0.61,2.34)$} \\
\hline \multicolumn{2}{|l|}{$2.31(1.49,3.59)$} \\
\hline & 0.003 \\
\hline \multicolumn{2}{|l|}{$0.43(0.21,0.86)$} \\
\hline \multicolumn{2}{|l|}{$1.65(1.06,2.59)$} \\
\hline & 0.12 \\
\hline \multicolumn{2}{|l|}{$1.07(0.52,2.19)$} \\
\hline \multicolumn{2}{|l|}{$2.08(1.32,3.26)$} \\
\hline & 0.045 \\
\hline \multicolumn{2}{|l|}{$1.05(0.56,1.96)$} \\
\hline \multicolumn{2}{|l|}{$2.31(1.46,3.66)$} \\
\hline & 0.218 \\
\hline \multicolumn{2}{|l|}{$1.31(0.78,2.20)$} \\
\hline \multicolumn{2}{|l|}{$2.05(1.20,3.51)$} \\
\hline & 0.717 \\
\hline \multicolumn{2}{|l|}{$1.75(1.15,2.66)$} \\
\hline \multicolumn{2}{|l|}{$2.11(0.81,5.50)$} \\
\hline \multirow{2}{*}{\multicolumn{2}{|c|}{$2.24(1.40,3.56)$}} \\
\hline & \\
\hline $0.85(0.45,1.59)$ & \\
\hline
\end{tabular}

Figure 1 The stratified analysis for unadjusted HR in the subgroups of potential confounding factors. HR (vs continued)=HR ratio.

Finally, we established an MI cohort to perform univariate and multivariate analyses using complete-case analysis as a sensitivity analysis. As shown in table 3 , the results were similar to those of the initial cohort adjusted for potential cofounders.

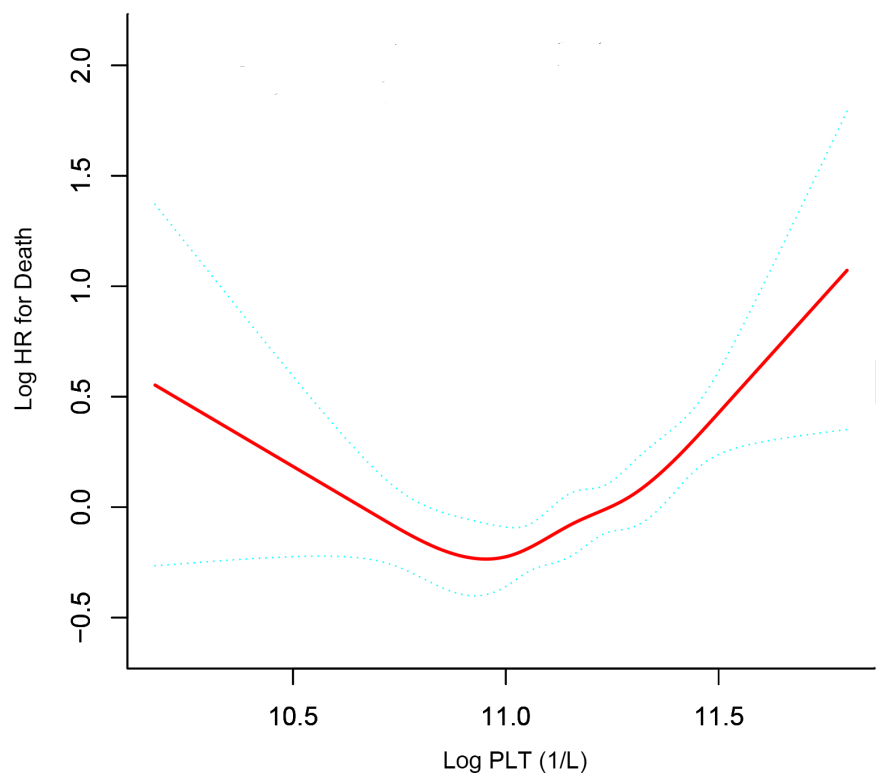

Figure 2 Smooth curves between platelet count and hepatocellular carcinoma. The model adjusted of gender, Child-Pugh class $(A, B)$, age $(<55, \geq 55) \times$ diameter of main tumour $(\leq 50,>50)$, both lobe with lesions (no, yes) $\times$ number of the intrahepatic lesions $(\leq 3,>3)$, AFP $(<25, \geq 25)$, LDH $(<245, \geq 245)$. LDH, lactic dehydrogenase;Log PLT, logarithm platelet count; AFP,alpha-fetoprotein.

\section{DISCUSSION}

In this large-scale, hospital-based, retrospective cohort study, we found that a higher PLT was associated with worse HCC OS for patients with BCLC stage B, which was consistent with the findings of previous studies. ${ }^{17-19}$ We further revealed a U-shaped relationship between PLT and HCC OS at the inflexion point of $67.6 \times 10^{9} / \mathrm{L}$. Additionally, we identified the high-risk subgroup with age $<55$, both lobes with lesions, tumour diameter $>50, \mathrm{Hgb} \geq 120$ and $\mathrm{CRP}>10$. To the best of our knowledge, this clinical study first demonstrated

Table 4 Threshold effect analysis for platelet count in the initial cohort using two-piecewise Cox proportional hazards model

\begin{tabular}{|c|c|c|}
\hline & $\begin{array}{l}\text { Unadjusted HR } \\
(95 \% \mathrm{Cl})\end{array}$ & $\begin{array}{l}\text { Adjusted HR } \\
(95 \% \mathrm{Cl})^{\star}\end{array}$ \\
\hline $\begin{array}{l}\text { The one-line Cox } \\
\text { proportional hazards } \\
\text { model }\end{array}$ & 1.73 (1.20 to 2.52$)$ & 1.91 (1.28 to 2.85$)$ \\
\hline \multicolumn{3}{|c|}{ The two-piecewise Cox proportional hazards model } \\
\hline$<10.83$ & $0.16(0.05$ to 0.55$)$ & 0.12 (0.03 to 0.52$)$ \\
\hline$\geq 10.83$ & 2.74 (1.76 to 4.28$)$ & 3.07 (1.91 to 4.92$)$ \\
\hline $\begin{array}{l}\mathrm{P} \text { for log-likelihood ratio } \\
\text { test }\end{array}$ & $<0.001$ & $<0.001$ \\
\hline
\end{tabular}

A log-likelihood ratio test was used to compare the one-line linear regression.

*This model was adjusted for gender, Child-Pugh class (A, B), age $(<55, \geq 55) \times$ diameter of main tumour $(\leq 50,>50)$, both lobe with lesions (no, yes) $\times$ number of the intrahepatic lesions $(\leq 3$, $>3)$, AFP $(<25, \geq 25)$, LDH $(<245, \geq 245)$.

AFP, Alpha-fetoprotein; LDH, lactic dehydrogenase. 


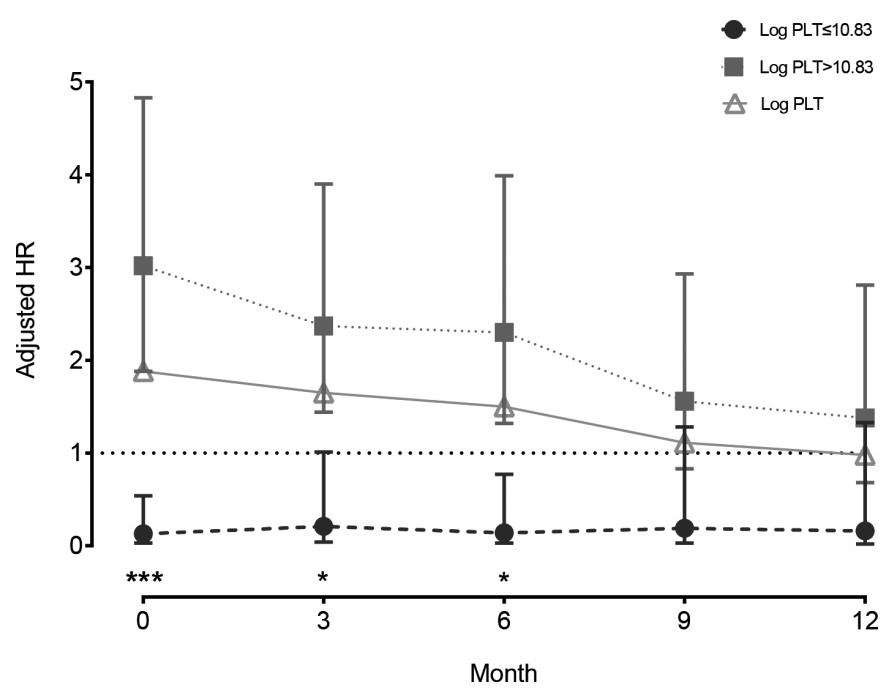

Figure 3 Landmark analyses of overall survival for patients surviving $>3,>6,>9$ and $>12$ months. HRs for the linear and non-linear relationship of platelet count with HCC overall survival were evaluated by Cox proportional hazards model. The log-likelihood ratio test was conducted to compare the one-line linear regression. HCC, hepatocellular carcinoma; Log PLT, logarithmplatelet count.

a non-linear relationship between PLT and HCC OS for patients with BCLC stage B.

In several extensive population-based cohort studies, oral aspirin is associated with a dose-dependent reduction in HCC risk. ${ }^{22-25}$ A significant chemopreventive effect of aspirin was found in men or younger individuals, ${ }^{22} 24$ which indirectly supports the conclusion of this study. In secondary prevention, the inverse relationship between antiplatelet therapy and HCC recurrence was further confirmed by liver resection, transarterial embolisation and sorafenib. ${ }^{26-28}$ A large retrospective study revealed that aspirin/clopidogrel use reduced the risk of HCC recurrence to $27 \%$ and the risk of overall mortality to $43 \%$ in patients with HBV-related HCC after liver resection. Additionally, antiplatelet treatment was related to lower recurrence risk in patients younger than 50 years and female patients. ${ }^{26}$ Moreover, the evidence from a smallscale cohort study suggests that aspirin use improves liver function test results and survival after TACE for HCC but not response or time to progression. ${ }^{27}$

Our study has some strengths, including the secondary analysis of a large, well-characterised HCC population with retrospective clinical data with more than 115.3 months of follow-up. First, we found that a U-shaped relationship between PLT and HCC OS was calculated through restricted cubic spline regression, and the threshold effect was calculated through a two-piecewise Cox proportional hazards model. We thus identified a specific interval of PLT to improve antiplatelet therapy in HCC. Second, the interaction of confounding factors was taken into consideration, which will evaluate the HRs of HCC death more accurately. Third, we also considered the non-linear relationship of confounders with HCC death. Moreover, we performed model II with adjustment for potential confounding factors through restricted cubic spline regression.

Our study also has limitations. First, we used data collected retrospectively from a single centre. Therefore, bias could be caused by residual and unmeasured confounders. However, the sensitivity analysis indicated that the PLT-HCG death association was robust in all models. We further performed a landmark analysis to evaluate the potential immortal time bias, and the threshold effect was no longer significant for patients surviving over 9 months. Second, in this secondary analysis, the inherent limitations of raw data were unavoidable. We established an MI cohort, and the core results with missing data tended to be underestimated. Additionally, the treatment regime was not available from the raw data. Third, our conclusions might be not suitable for patients with HCC induced by alcohol or other causes.

In conclusion, our study showed a U-shaped relationship between PLT and HCC OS at the inflection point of $67.6 \times 10^{9} / \mathrm{L}$. Additionally, a significantly higher hazard risk was found in the patients with age $<55$, both lobes with lesions, tumour diameter $>50, \mathrm{Hgb} \geq 120$ and $\mathrm{CRP}>10$.

\section{Author affiliations}

${ }^{1}$ Department of Oncology, 900th Hospital of PLA, Fuzhou, China

${ }^{2}$ Department of Medical Oncology, Xiamen Branch, Zhongshan Hospital, Fudan University, Shanghai, China

${ }^{3}$ Fujian Center for Safety Evaluation of New Drug, Fujian Medical University, Fuzhou, China

${ }^{4}$ Department of Hepatobiliary Disease, 900th Hospital of PLA, Fuzhou, China ${ }^{5}$ Department of Neurology, 900th Hospital of PLA, Fuzhou, China

Acknowledgements We gratefully thank for the statistical support from Empower $\mathrm{U}$ team of the Department of Epidemiology and Biostatistics, X\&Y Solutions in Boston. We are also grateful to Dr Xuewen Wang and Yayin Chen for their work in collecting data.

Contributors Conception and design: LL, ZS, XC. Collection and assembly of data: $\mathrm{SL}, \mathrm{YZ}$, JL. Data analysis and interpretation: LL, XC. Manuscript writing: LL, ZW, PZ, $H H, X C$. Final approval of manuscript: All authors.

Funding The National Natural Science Foundation of China (Nos 81502360); the Natural ScienceFoundation of Fujian Province (Nos 2018J01352 and 2016J01576 and 2016J01586); the Science andTechnology Innovation Joint Foundation of Fujian Province(Nos 2017Y9125).

Competing interests None declared.

Patient consent for publication Not required.

Provenance and peer review Not commissioned; externally peer reviewed.

Data availability statement Data are available in a public, open access repository. the raw data were freely obtained from the Dryad Digital Repository database ( www.Datadryad.org; Dryad data package: Shen, Lujun et al (2019), Data from: Dynamically prognosticating patients with hepatocellular carcinoma through survival paths mapping based on time-series data, Dryad, Dataset, https://doi.org/ 10.5061/dryad.pd44k8r).

Supplemental material This content has been supplied by the author(s). It has not been vetted by BMJ Publishing Group Limited (BMJ) and may not have been peer-reviewed. Any opinions or recommendations discussed are solely those of the author(s) and are not endorsed by BMJ. BMJ disclaims all liability and responsibility arising from any reliance placed on the content. Where the content includes any translated material, BMJ does not warrant the accuracy and reliability of the translations (including but not limited to local regulations, clinical guidelines, terminology, drug names and drug dosages), and is not responsible for any error and/or omissions arising from translation and adaptation or otherwise. 
Open access This is an open access article distributed in accordance with the Creative Commons Attribution Non Commercial (CC BY-NC 4.0) license, which permits others to distribute, remix, adapt, build upon this work non-commercially, and license their derivative works on different terms, provided the original work is properly cited, appropriate credit is given, any changes made indicated, and the use is non-commercial. See: http://creativecommons.org/licenses/by-nc/4.0/.

ORCID iD

Xiong Chen http://orcid.org/0000-0001-5316-6512

\section{REFERENCES}

1 Jemal A, Bray F, Center MM, et al. Global cancer statistics. Cancer J Clin 2011;61:69-90.

2 Zhou M, Wang $\mathrm{H}$, Zeng $\mathrm{X}$, et al. Mortality, morbidity, and risk factors in China and its provinces, 1990-2017: a systematic analysis for the global burden of disease study 2017. Lancet 2019;394:1145-58.

3 Villanueva A. Hepatocellular carcinoma. N Engl J Med 2019;380:1450-62.

4 Wu C-Y, Lin J-T, Ho HJ, et al. Association of nucleos(t)ide analogue therapy with reduced risk of hepatocellular carcinoma in patients with chronic hepatitis B: a nationwide cohort study. Gastroenterology 2014:147:143-51.

5 Wu C-Y, Chen Y-J, Ho HJ, et al. Association between nucleoside analogues and risk of hepatitis B virus-related hepatocellular carcinoma recurrence following liver resection. JAMA 2012;308:1906-14.

6 Pavlovic N, Rani B, Gerwins P, et al. Platelets as key factors in hepatocellular carcinoma. Cancers 2019;11

7 Lavergne M, Janus-Bell E, Schaff M, et al. Platelet integrins in tumor metastasis: do they represent a therapeutic target? Cancers 2017;9

8 Malehmir M, Pfister D, Gallage S, et al. Platelet GPIbo is a mediator and potential interventional target for NASH and subsequent liver cancer. Nat Med 2019;25:641-55.

9 El-Serag HB, Kanwal F, Davila JA, et al. A new laboratory-based algorithm to predict development of hepatocellular carcinoma in patients with hepatitis $\mathrm{C}$ and cirrhosis. Gastroenterology 2014;146:1249-55.

10 Pinato DJ, Stebbing J, Ishizuka M, et al. A novel and validated prognostic index in hepatocellular carcinoma: the inflammation based index (IBI). J Hepatol 2012;57:1013-20.

11 Pang Q, Bi J-B, Xu X-S, et al. King's score as a novel prognostic model for patients with hepatitis B-associated hepatocellular carcinoma. Eur J Gastroenterol Hepatol 2015;27:1337-46.

12 loannou GN, Green P, Kerr KF, et al. Models estimating risk of hepatocellular carcinoma in patients with alcohol or NAFLD-related cirrhosis for risk stratification. J Hepatol 2019;71:523-33.

13 Hu B, Yang X-R, Xu Y, et al. Systemic immune-inflammation index predicts prognosis of patients after curative resection for hepatocellular carcinoma. Clin Cancer Res 2014;20:6212-22.

14 Chan AWH, Chan SL, Wong GLH, et al. Prognostic nutritional index (PNI) predicts tumor recurrence of very Early/Early stage hepatocellular carcinoma after surgical resection. Ann Surg Oncol 2015;22:4138-48.

15 Huang P-Y, Wang C-C, Lin C-C, et al. Predictive effects of inflammatory scores in patients with BCLC 0-A hepatocellular carcinoma after hepatectomy. J Clin Med 2019;8:1676.

16 Zhu G-Q, Wang K, Wang B, et al. Aspartate aminotransferase-toplatelet ratio index predicts prognosis of hepatocellular carcinoma after postoperative adjuvant transarterial chemoembolization. Cancer Manag Res 2019;11:63-79.

17 Lee C-H, Lin Y-J, Lin C-C, et al. Pretreatment platelet count early predicts extrahepatic metastasis of human hepatoma. Liver Int 2015;35:2327-36.

18 Xue T-C, Ge N-L, Xu X, et al. High platelet counts increase metastatic risk in huge hepatocellular carcinoma undergoing transarterial chemoembolization. Hepatol Res 2016;46:1028-36.

19 Han S, Lee S, Yang JD, et al. Risk of posttransplant hepatocellular carcinoma recurrence is greater in recipients with higher platelet counts in living donor liver transplantation. Liver Transp/ 2018;24:44-55.

20 Scheiner B, Kirstein M, Popp S, et al. Association of platelet count and mean platelet volume with overall survival in patients with cirrhosis and unresectable hepatocellular carcinoma. Liver Cancer 2019;8:203-17.

21 Shen L, Zeng Q, Guo P, et al. Dynamically prognosticating patients with hepatocellular carcinoma through survival paths mapping based on time-series data. Nat Commun 2018;9:2230.

22 Lee T-Y, Hsu Y-C, Tseng H-C, et al. Association of daily aspirin therapy with risk of hepatocellular carcinoma in patients with chronic hepatitis B. JAMA Intern Med 2019;179:633-40.

23 Simon TG, Ma Y, Ludvigsson JF, et al. Association between aspirin use and risk of hepatocellular carcinoma. JAMA Oncol 2018;4:1683-90.

24 Hwang IC, Chang J, Kim K, et al. Aspirin use and risk of hepatocellular carcinoma in a national cohort study of Korean adults. Sci Rep 2018;8:4968.

25 Petrick JL, Sahasrabuddhe VV, Chan AT, et al. Nsaid use and risk of hepatocellular carcinoma and intrahepatic cholangiocarcinoma: the liver cancer pooling project. Cancer Prev Res 2015;8:1156-62.

26 Lee P-C, Yeh C-M, Hu Y-W, et al. Antiplatelet therapy is associated with a better prognosis for patients with hepatitis $B$ virus-related hepatocellular carcinoma after liver resection. Ann Surg Oncol 2016;23:874-83.

27 Boas FE, Brown KT, Ziv E, et al. Aspirin is associated with improved liver function after embolization of hepatocellular carcinoma. AJR Am $J$ Roentgenol 2019;213:1-7.

28 Li S, Dai W, Mo W, et al. By inhibiting PFKFB3, aspirin overcomes sorafenib resistance in hepatocellular carcinoma. Int $J$ Cancer 2017; 141:2571-84. 